\title{
CHANGES IN FRESHWATER ECOSYSTEM SERVICES FROM 1960 TO 2017 UNDER CLIMATE CHANGE IN GUIZHOU, CHINA
}

\author{
HAN, H. Q. ${ }^{1 *}-$ YANG, G. B. $^{2}-$ ZHANG, Y. J. ${ }^{1}$ \\ ${ }^{1}$ School of Architecture and Urban Planning, Guizhou Institute of Technology, Guiyang 550003, \\ PR China \\ (e-mail: cgp1963@126.com-Y.J. Zhang) \\ ${ }^{2}$ School of Geographical and Environmental Sciences, Guizhou Normal University, Guiyang \\ 550025, PR China \\ (e-mail: 290857583@qq.com-G. B. Yang) \\ *Corresponding author \\ e-mail: hhuiqing2006@126.com; phone/fax:+86-137-6581-2715 \\ (Received $17^{\text {th }}$ Jul 2020; accepted $7^{\text {th }}$ Oct 2020)
}

\begin{abstract}
The supply capacity of freshwater ecosystem services (FES) is affected by climate change as a result of global temperature rising. However, previous studies have rarely focused on the interannual, seasonal, and periodic change characteristics of FES. We analyzed the effects of climate change on FES from 1960 to 2017 in the Guizhou Province in China. The water yield and soil retention in Guizhou at an annual scale exhibited a decreasing trend between 1960 and 2017, whereas the annual nutrient retention exhibited an increasing trend. The change trends of the three FES in spring and autumn were significantly different from the change trends in summer and winter. The change rate of the nutrient retention in all four seasons from 1960 to 2017 was opposite of that of the water yield and soil retention. The peak period of the water yield, soil retention, and nutrient retention at the annual scale occurred at 28 a (i.e. 28 year), whereas differences were observed for the peak period of the three FES at the seasonal scale. The results of this study benefit the scientific management of the FES and contribute to reducing the negative effects of global climate warming.
\end{abstract}

Keywords: ecosystem service change, climate impact, spatial pattern, change period, InVEST model, Guizhou

\section{Introduction}

Ecosystems are the basis for human survival and socioeconomic development and are critical support systems for all life on earth (Karp et al., 2015; Rau et al., 2018). Ecosystems provide humans with a variety of important services (e.g., biodiversity, carbon storage, soil retention, recreation, and grain production) that constitute the basis for the sustainable development of human society and economy (Costanza et al., 2014; Lee and Lautenbach, 2016). However, many ecosystem services have deteriorated in the past decades due to changes in the natural environment and increasing intensive human activities (Ma, 2005; Cerretelli et al., 2018). Therefore, research on ecosystem services is a topic of broad and current interest in many countries and regions (Dittrich et al., 2017; Dvarskas, 2018; Qiao et al., 2019).

Previous studies have indicated that natural environmental changes and human activities are important factors affecting ecosystem functions ( $\mathrm{Su}$ and $\mathrm{Fu}, 2013$; Wang et al., 2016; Mahmoud and Gan, 2018). As one of the key factors, climate change has affected ecosystem services by influencing the climate elements and climate-related factors (e.g., land use change) (Mooney et al., 2009; Gosling, 2013; Grimm et al., 2016). Research on the impacts of climate change on agriculture, freshwater, marine, 
and forest ecosystem services has received considerable attention in many countries and regions (Costanza et al., 2011; Rocca et al., 2014; Maia et al., 2018; Huang et al., 2019). Lobell et al. (2011) found that the decline in food production in subtropical semi-arid regions was closely related to the reduction in precipitation. Future climate change will increase the occurrence and frequency of insect damage and thereby reduce the supply level of forest ecosystem services (Trumbore et al., 2015). Plant pollination will decline under the impacts of future climate change (Bartomeus et al., 2011). Furthermore, the loss of ecosystem service value is also a concern of many scholars. For example, Lam et al. (2016) observed that the global fishery income would decline by $35 \%$ by 2050 under a high $\mathrm{CO}_{2}$ emission scenario. However, previous studies have focused more on the analysis of the impact of climate change on ecosystem services for two or more time periods (Lorencová et al., 2013; Fu et al., 2017) and less on the interannual, seasonal, and periodic characteristics of the changes in FES.

Guizhou Province in China is not only an ecologically fragile region but also an area sensitive to global climate change (Zhang et al., 2015). Key FES such as water yield, soil retention, and nutrient retention are provided by abundant natural vegetation in Guizhou (Han and Dong, 2017a; Han et al., 2016). FES are highly sensitive to climate change (Ma, 2005; Bangash et al., 2013; Hoyer and Chang, 2014). Climate change in Guizhou has strongly affected fragile ecosystems, thereby influencing the availability of FES (Han and Dong, 2017b). However, its complex influence on FES in this region remains unclear. Therefore, we analyzed the impacts of climate change on FES from 1960 to 2017 using Guizhou Province as an example. The results provide an understanding of the response mechanism of FES to climate change and scientific reference data for addressing the negative effects of climate change on ecosystem service management.

The following hypotheses are tested in this study: (1) there are differences in the impacts of climate change on different FES; (2) there are annual and seasonal characteristics of FES changes under the impact of climate change; (3) there is a periodicity in the changes in FES resulting from climate change.

\section{Methodology}

\section{Study area}

Guizhou Province is located in southwestern China $\left(103^{\circ} 36^{\prime}-109^{\circ} 35^{\prime} \mathrm{E}, 24^{\circ} 37^{\prime}-\right.$ $29^{\circ} 13^{\prime} \mathrm{N}$ ) and covers an area of $176167 \mathrm{~km}^{2}$ (Fig. 1). The climate is a subtropical humid monsoon climate. The annual average temperature in most parts of Guizhou is approximately $15{ }^{\circ} \mathrm{C}$. The average temperature in January is $3-6{ }^{\circ} \mathrm{C}$ and the average temperature in July is $22-25{ }^{\circ} \mathrm{C}$. The annual average precipitation is approximately $1100 \mathrm{~mm}$ (Han and Dong, 2017a). The temperature in Guizhou Province tends to show an increasing trend, while the amount of precipitation exhibits a decreasing trend over the past few decades (Ma et al., 2013). The topography is high in the west but low in the east. The main categories of landforms include plateau, mountain, hill and basin, with the mountainous areas accounting for $61.7 \%$ of the total across Guizhou Province (Han et al., 2020). The complex and diversified vegetation categories are attributed to the specific geographical conditions and the complications of topography (Han et al., 2019). An ecologically fragile Karst region consisting of carbonate rocks covers $13 \times 10^{4} \mathrm{~km}^{2}$ and has the characteristics of low environmental capacity, instability, and low resilience (Zhang et al., 2002). 


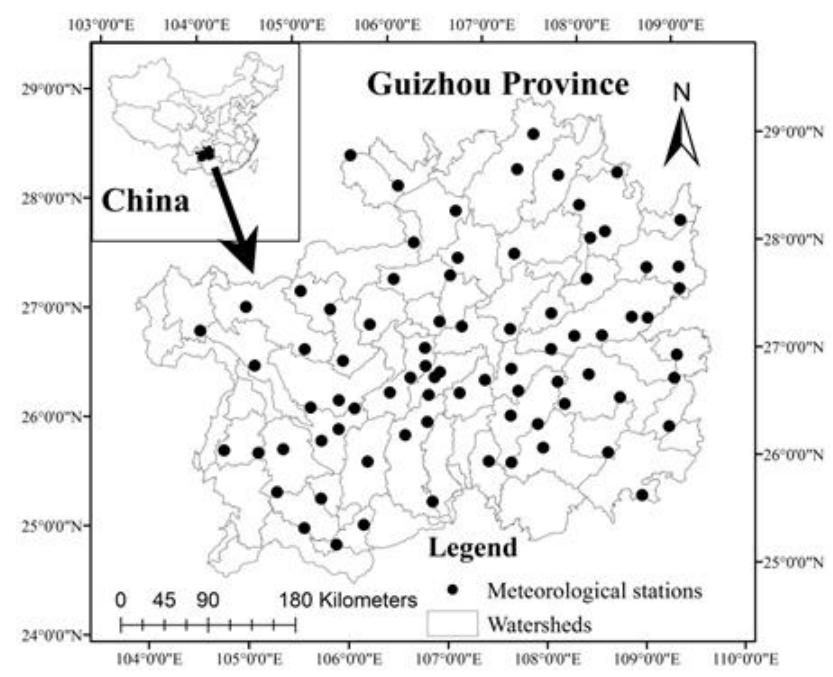

Figure 1. Location of study site

\section{Data source}

The daily observation data of 84 meteorological stations from 1960 to 2017 in Guizhou was provided by the climate center of Guizhou. The land use data were obtained by interpreting Landsat $\mathrm{ETM}^{+}$remote sensing images from 2015 . The soil data were provided by the soil database of China. The 30-m elevation data (ASTER GDEM) were downloaded from the Geospatial Data Cloud in China (http://www.gscloud.cn).

\section{Methods}

\section{Assessment of FES}

We assessed the FES in Guizhou by using the InVEST model, which was developed by Stanford University, the World Wide Fund for Nature, and the Nature Conservancy (Sharp et al., 2014). The parameters we used in the InVEST model were based on the research results of Han and Dong (2017a) and Han et al. (2016). We assume the climate change with no land use change from 1960 to 2017.

(1) Water yield

The water yield assessment was based on the Budyko curve (Budyko and Miller, 1974) and precipitation data:

$$
\begin{gathered}
Y_{x j}=\left(1-\frac{A E T_{x j}}{P_{x j}}\right) \bullet P_{x} \\
\frac{A E T_{x j}}{P_{x}}=\frac{1+\omega_{x} R_{x j}}{1+\omega_{x} R_{x j}+\frac{1}{R_{x j}}} \\
\omega_{x}=Z \frac{A W C_{x}}{P_{x}}
\end{gathered}
$$




$$
R_{x j}=\frac{k_{x j} \bullet E T_{o}}{P_{x}}
$$

where $Y$ is the water yield, $A E T$ is the actual evapotranspiration, $P$ is the precipitation, $\omega$ is a non-physical parameter of climate and soil, $R$ is the Budyko aridity index, $Z$ is the coefficient used by Zhang, $A W C$ is the available soil moisture, $K$ is the vegetation evapotranspiration coefficient; the evapotranspiration was calculated using the FAO56 Penman-Monteith equation (Allen et al., 1998).

(2) Soil retention

The soil retention was calculated using the Universal Soil Loss Equation (USLE):

$$
\begin{gathered}
W=R K L S-U S L E \\
U S L E=R \cdot K \cdot L \cdot S \cdot C \cdot P
\end{gathered}
$$

where $W$ is the amount of soil retention, $R K L S$ is the maximum soil erosion (assuming there is no vegetation on the ground), $R$ is the rainfall erosivity, which is calculated using the method of Zhang and Fu (2003), $K$ is the soil erodibility, which is calculated using the method of Zhou et al. (2005), $L$ is the slope length, $S$ is the slope, $C$ represents the vegetation cover and management factors, and $P$ is the engineering factor.

\section{(3) Nutrient retention}

The retention of nitrogen and phosphorus represented the nutrient retention in this model (Redhead et al., 2018):

$$
\begin{gathered}
W P_{i}=1 / A L V_{i} \\
A L V_{i}=H S S_{i} \bullet \text { pol }_{i} \\
H S S_{i}=\lambda_{i} / \lambda_{w} \\
\lambda_{i}=\log \left(\sum_{u} Y_{u}\right)
\end{gathered}
$$

where $W P$ is the nutrient retention value, $A L V$ is the pollution load, pol is the output coefficient, HSS is the hydrological sensitivity, $\lambda_{i}$ is the runoff coefficient, $\lambda_{w}$ is the average runoff coefficient, and $\sum_{u} Y_{u}$ is the water yield.

\section{Trend analysis}

A linear regression analysis was used to determine the change trend of the FES; the slope of the equation represents the rate of change (Wei, 2007):

$$
y=a t+b
$$


where $t$ is time, $a$ is the slope of the regression equation, and $b$ is the constant of the regression equation. A slope $>0$ represents an increasing trend in FES and a slope $<0$ represents a decreasing trend. The results are evaluated using the F-criterion.

\section{Periodicity analysis}

A wavelet analysis was used in this study to determine the periodic characteristics of the changes in FES (Torrence and Compo, 1998). This method is a time-scale analysis that detects changes in the signal frequency over time; it has been widely applied for periodicity analyses of hydrological and meteorological change (e.g., precipitation change over time) (Charlier et al., 2015; Yi and Shu, 2012).

$$
\begin{gathered}
\psi(t)=e^{i c t} e^{-t 2 / 2} \\
W f(a, b)=|a|^{-1 / 2} \int_{-\infty}^{+\infty} f(t) \psi \cdot \frac{(t-b)}{a} d t
\end{gathered}
$$

where $c$ is a constant, $i$ is the imaginary part, $W f(a, b)$ is the wavelet transform coefficient, $f(t)$ is the signal analysis function, $a$ is the amplification factor, $b$ is the shift factor, and $\psi^{\bullet}$ is the conjugate function of the wavelet function.

\section{Results}

\section{Water yield}

The slope of the regression equation for the change in annual water yield change across Guizhou was -0.6242 , which indicates a downward trend for annual water yield $(P<0.05)$. The slope of the regression equation for the change to water yield in spring and autumn across the study area was -0.4406 and -0.7781 , respectively, suggesting a declining trend of water yield in spring and autumn $(P<0.05)$. The slope of the regression equation for the change to water yield in the summer and winter was 0.4525 and 0.1369 , suggesting an increasing trend of water yield in summer and winter $(P<0.05)$ (Fig. 2).

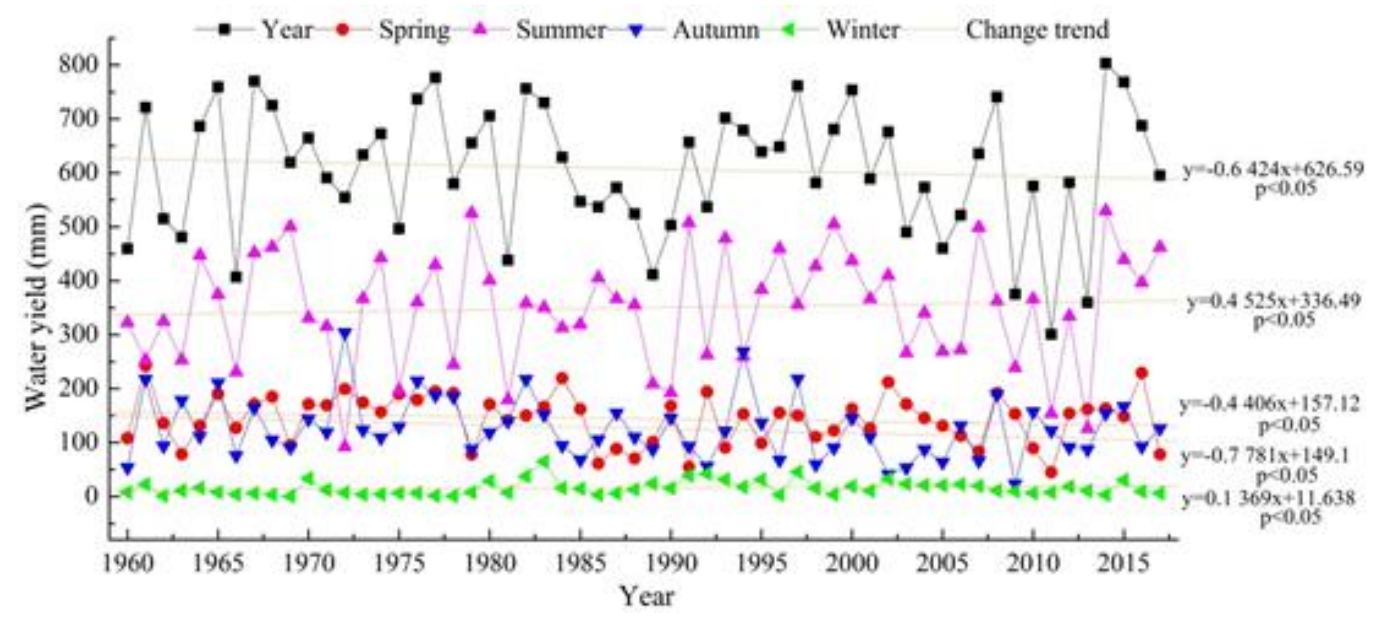

Figure 2. Inter-annual change in the water yield in Guizhou from 1960 to 2017 
The amount of annual water yield during the periods of 1970-1979 and 1990-1999 was $636 \mathrm{~mm}$ and $639 \mathrm{~mm}$, respectively, higher than in the periods 1980 and 1989, 2000 and 2009, as well as 2010 and $2017(615 \mathrm{~mm}, 585 \mathrm{~mm}, 582 \mathrm{~mm}$ and $584 \mathrm{~mm})$. The amount of water yield in spring and autumn $(170 \mathrm{~mm}$ and $160 \mathrm{~mm})$ during the period from 1970 to 1979 was higher than in other decades. While the amount of water yield in summer during the periods from 1960 to 1969 and from 1990 to 1999 (362 mm and $383 \mathrm{~mm}$ ) was higher than in other decades. The amount of water yield in winter during such periods as 1980-1989, 1990-1999 and 2000-2009 was $22 \mathrm{~mm}, 25 \mathrm{~mm}$ and $19 \mathrm{~mm}$, respectively, higher than in such periods between 1960 and 1969, 1970 and 1979, as well as 2010 and 2017 (Fig. 3).

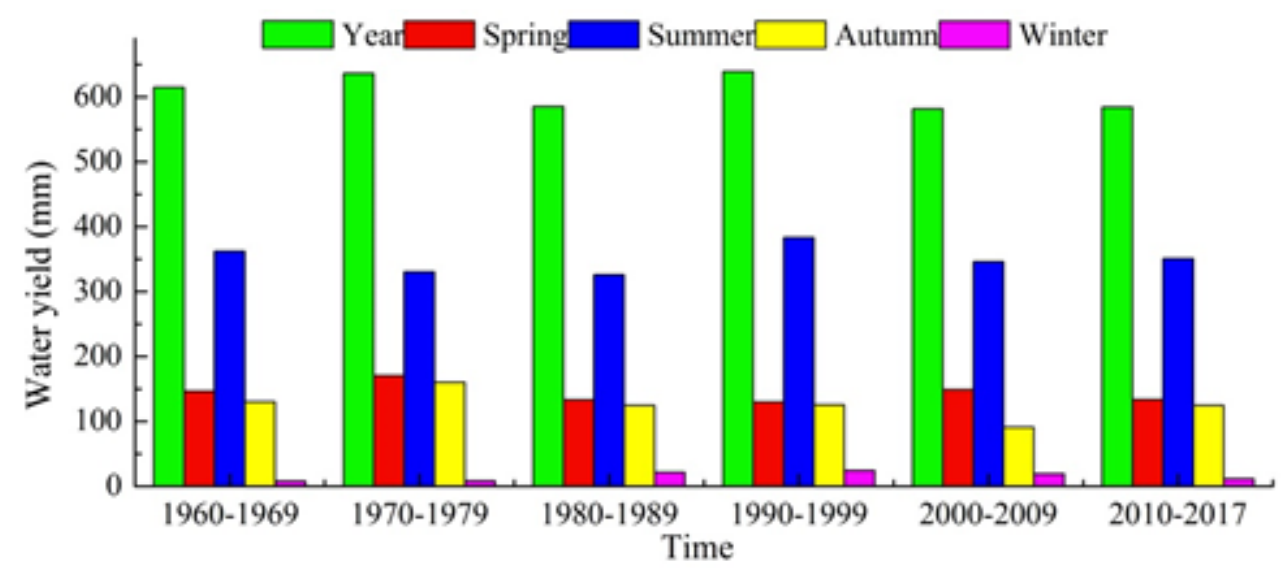

Figure 3. Changes in the water yield in Guizhou for six decades

The annual water yield decreased in the central, western, and northern parts of Guizhou whereas in increased in the eastern and southeastern parts (Fig. 4e). The water yield in spring and autumn exhibited a decreasing trend in most areas of Guizhou, except for the southeastern part (Fig. 4a, b). The summer and winter water yield exhibited an increasing trend in most areas of Guizhou, except for some regions in the western part (Fig. 4c, d).

Two periodic oscillations were observed in the annual change in water yield in Guizhou from 1960 to 2017; 6a and 28a were the peak years and the highest peak occurred in 28a (Fig. 5e). There were five periodic oscillations in the change in water yield in the spring and 5a, 9a, 13a, 18a, and 29a were the peak years and the latter had the highest peak (Fig. 5a). There were four periodic oscillations in the summer and 4a, 8a, 15a, and 28a (highest peak) were the peak years (Fig. 5b). There were four periodic oscillations in the autumn and 5a, 8a, 17a, and 28a (highest peak) were the peak years (Fig. 5c). There were three periodic oscillations in the winter and $4 \mathrm{a}, 7 \mathrm{a}$, and $17 \mathrm{a}$ (highest peak) were the peak years (Fig. 5d).

\section{Soil retention}

The annual soil retention in Guizhou exhibited an increasing trend during 1960-2017 $(P<0.05)$. The amount of soil retention decreased in spring and autumn and increased in summer and winter $(P<0.05)$. The slope of the regression equation for the change to soil retention in summer (1.394) was higher than in spring, autumn and winter $(-0.3683$, -0.1828 and 0.1937) $(P<0.05)$ (Fig. 6). 


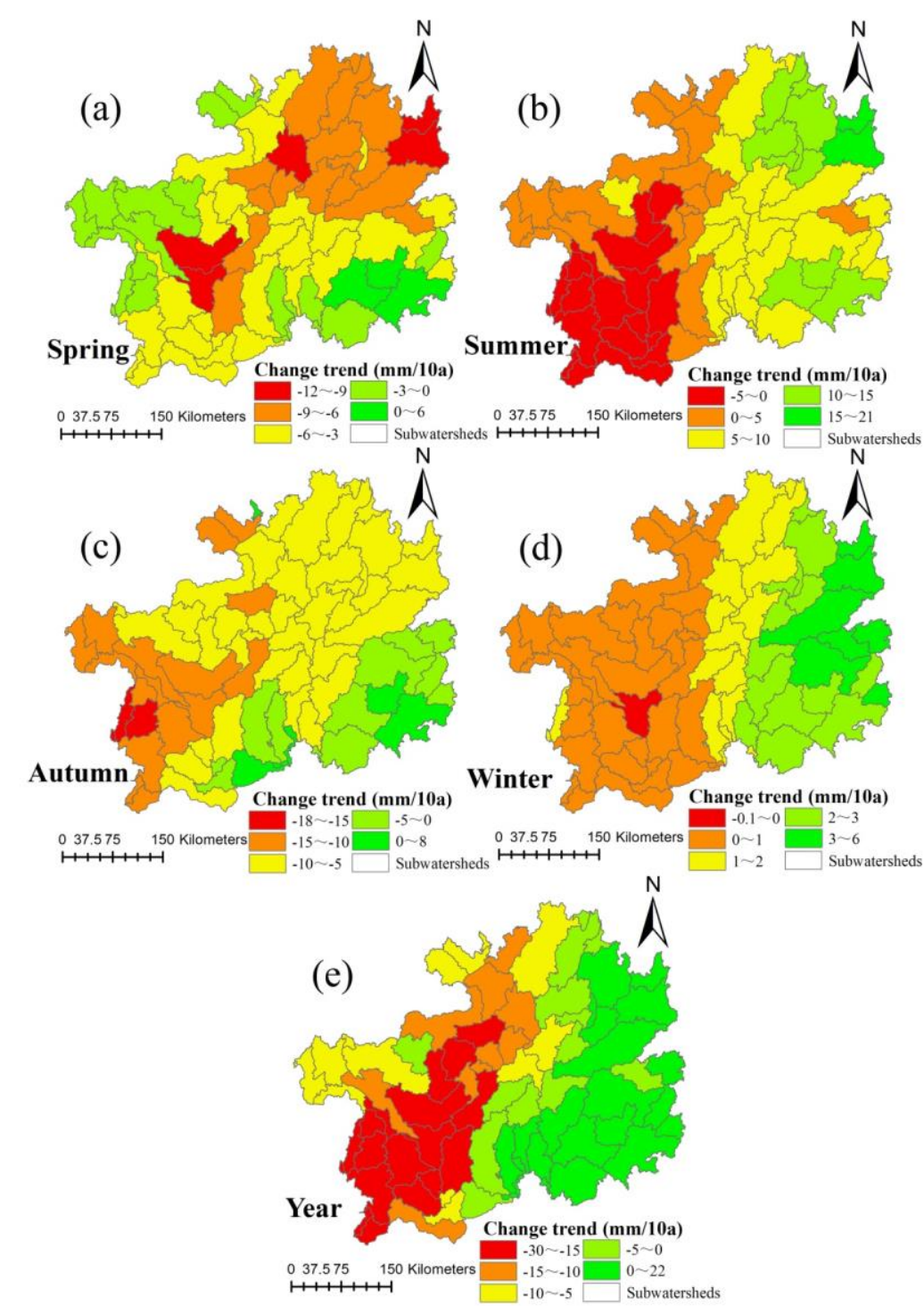

Figure 4. Spatial pattern of the changes in the water yield in Guizhou at annual and seasonal scales from 1960 to 2017

The decade of 1990-1999 showed the highest level of annual soil retention (1181 t/ha), while the low levels of soil retention observed during such periods as 19701979 and 1980-1989 (1041 t/ha and $1027 \mathrm{t} / \mathrm{ha}$ ). The levels of soil retention in summer for six decades exceeded $550 \mathrm{t} / \mathrm{ha}$, while those in spring, autumn, and winter for six decades fell below 300 t/ha (Fig. 7).

The annual soil retention exhibited an increasing trend from 1960 to 2017 in most parts of Guizhou, except for the northwestern and southwestern parts (Fig. 8e). Most areas in Guizhou showed decreases in the soil retention in spring and autumn. The areas of increasing soil retention in the spring were located in the northern part of Guizhou, whereas the areas of increasing soil retention in the autumn were located in the eastern and southern parts (Fig. 8a,c). The summer soil retention exhibited an increasing trend in most parts of Guizhou, except for some small regions of the southwestern and northwestern parts of Guizhou (Fig. 8b). The winter soil retention increased in all areas of Guizhou (Fig. 8d). 


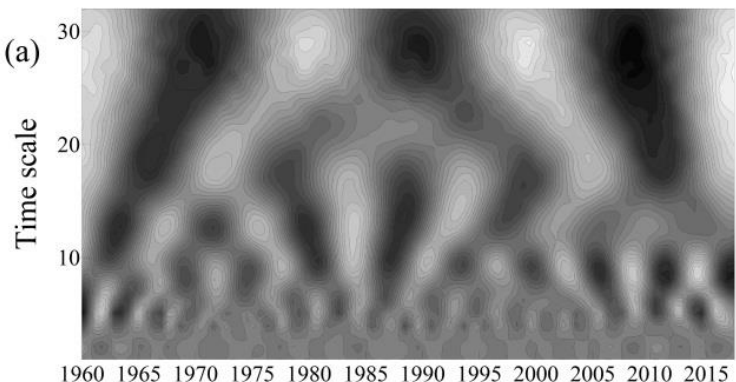
Spring

Years

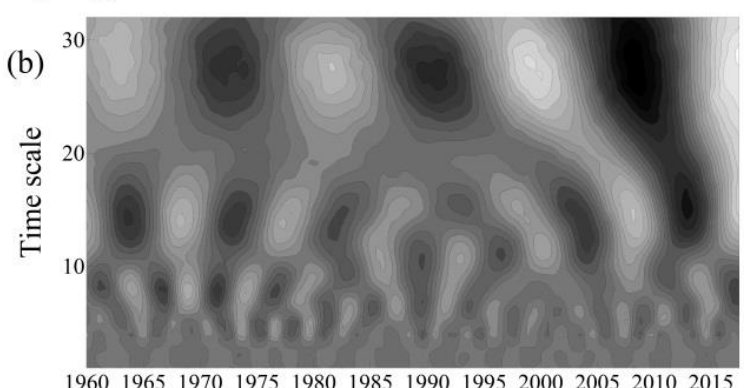

196019651970197519801985199019952000200520102015 Summer

Years

(c)

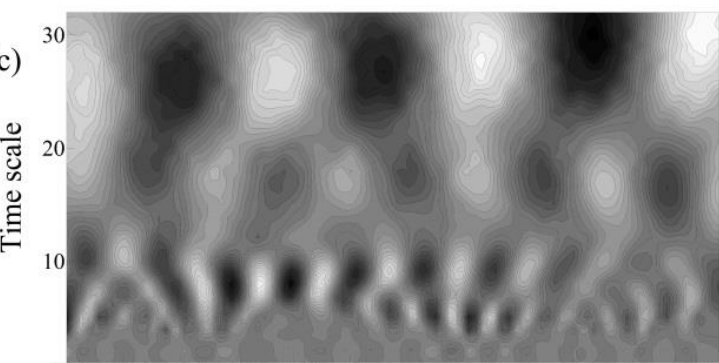

196019651970197519801985199019952000200520102015 Autumn Years

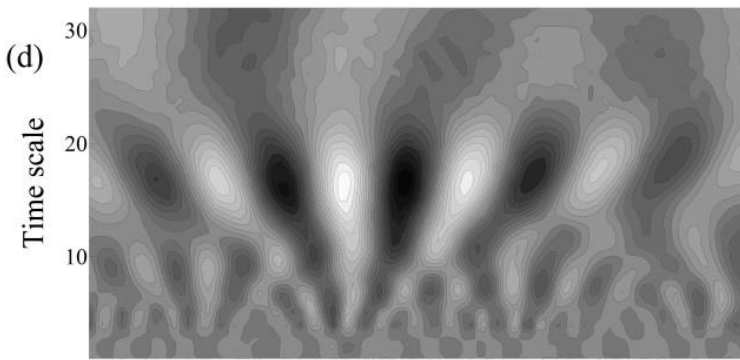

196019651970197519801985199019952000200520102015

$$
\text { Winter }
$$

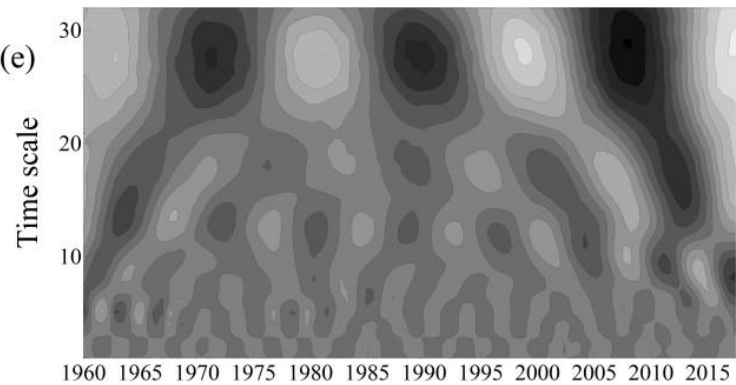

Year

Years
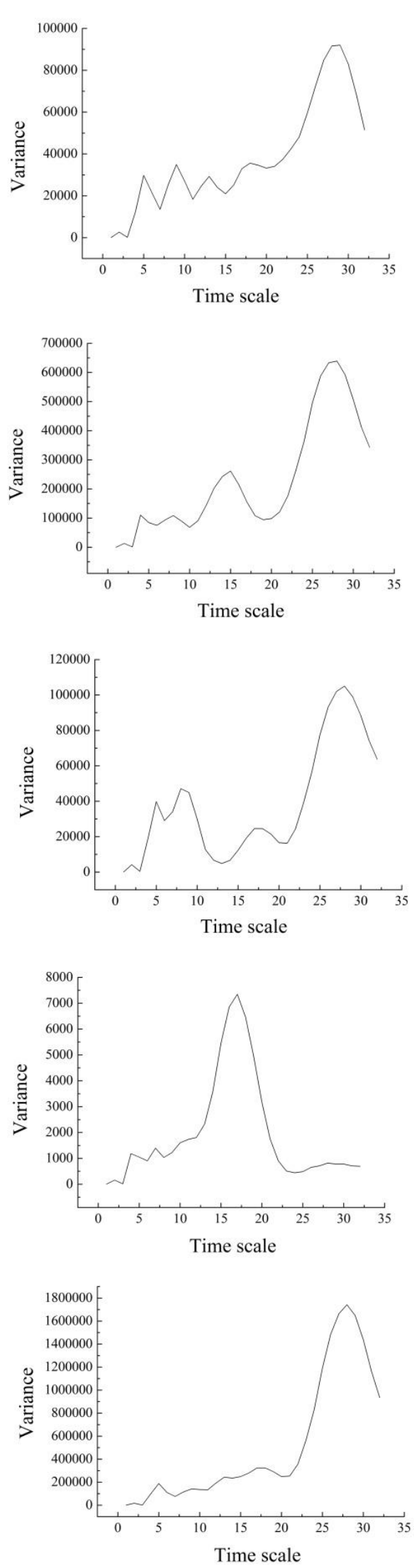

Figure 5. Periodicity of the water yield change in Guizhou at annual and seasonal scales from 1960 to 2017 


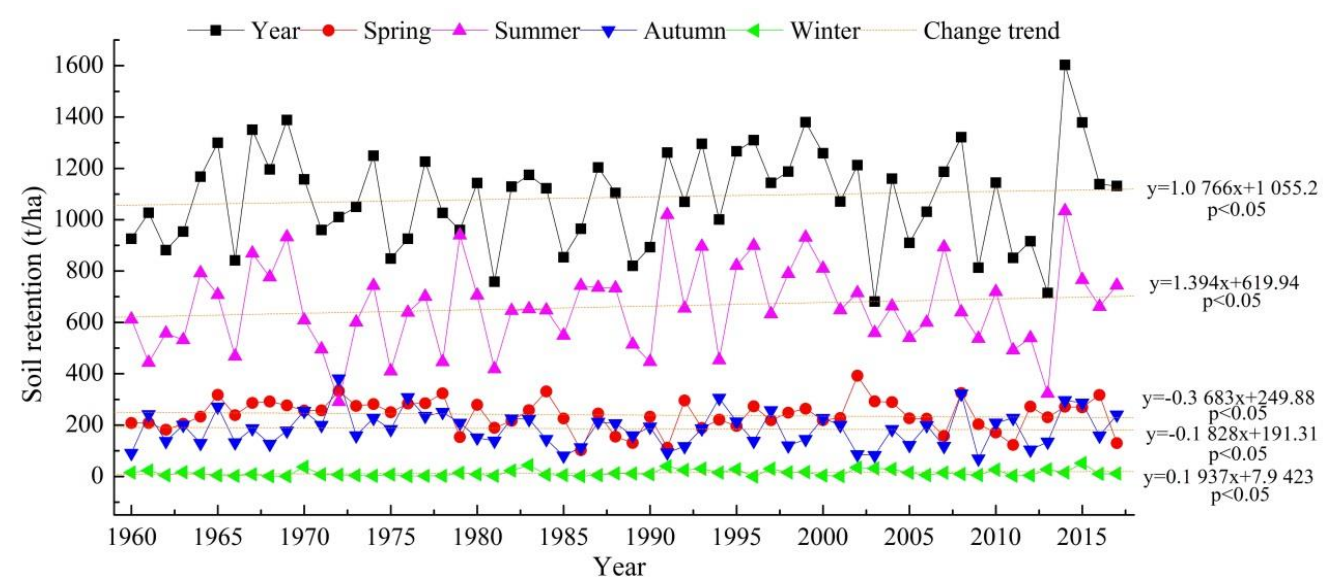

Figure 6. Inter-annual change in soil retention in Guizhou from 1960 to 2017

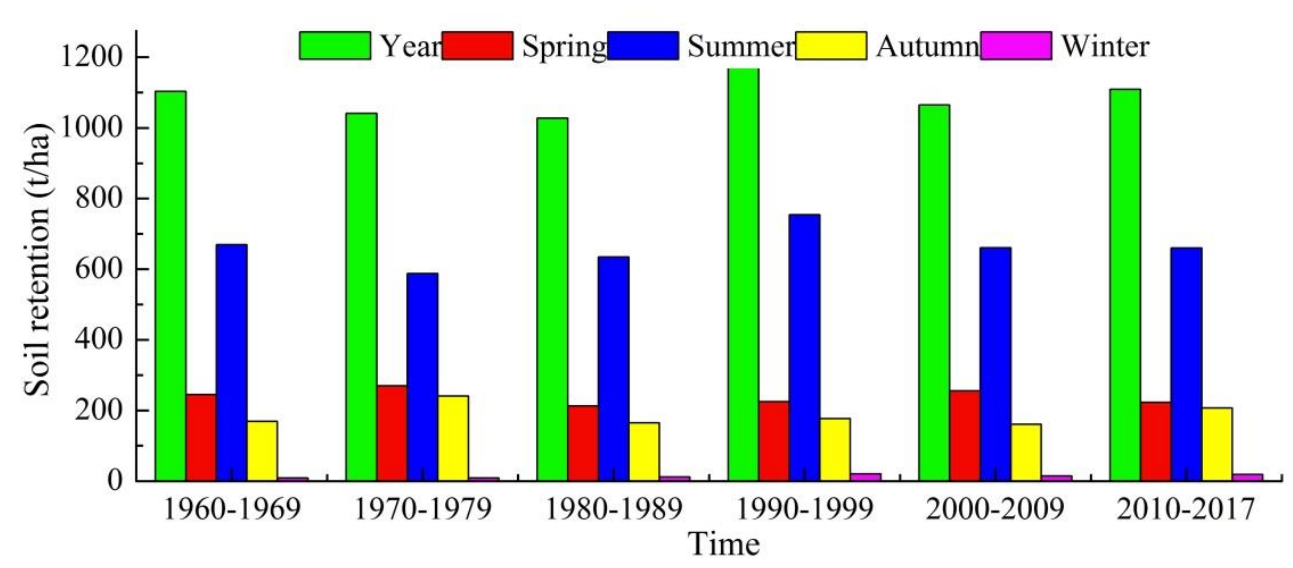

Figure 7. Changes in the soil retention in Guizhou for six decades

Three periodic oscillations were observed in the annual soil retention change in Guizhou between 1960 and 2017; the peak years included 7a, 15a, and 28a (highest peak) (Fig. 9e). Four periodic oscillations occurred for the spring soil retention change and the peak years included 4a, 9a, 13a, and 28a (highest peak) (Fig. 9a). Three periodic oscillations were observed for the summer soil retention change and the peak years included 7a, 15a, and 27a (highest peak) (Fig. 9b). There were four periodic oscillations in the autumn and the peak years included 5a, 9a, 17a, and 30a (highest peak) (Fig. 9c). Four periodic oscillations were observed for the winter and the peak years included 4a, 9a, 17a (highest peak), and 28a (Fig. 9d).

\section{Nutrient retention}

The annual nutrient retention in Guizhou exhibited an increasing trend between 1960 and $2017(P<0.05)$. The nutrient retention showed an increasing trend in spring and autumn, whereas a decreasing trend was observed for the summer and winter $(P<0.05)$. The slope of the regression equation for the change in nutrient retention was higher in spring (0.0213) than in autumn (0.0042). In contrast, the slope of the regression equation for the change to nutrient retention was greater in summer $(-0.0034)$ than in winter (-0.0018) $(P<0.05)$ (Fig. 10). 


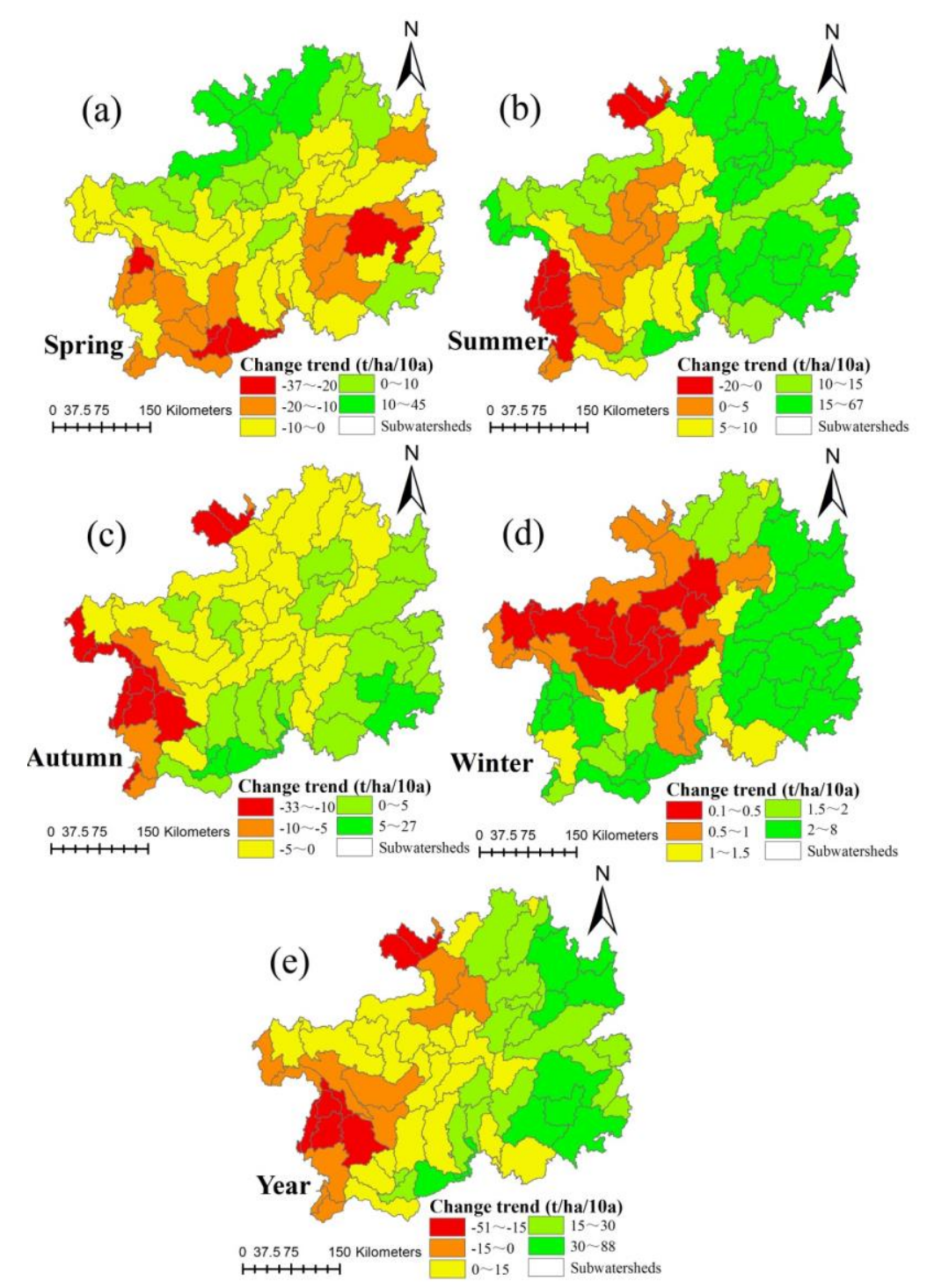

Figure 8. Spatial pattern of the changes in the soil retention in Guizhou at annual and seasonal scales from 1960 to 2017

The level of annual nutrient retention for six decades varied from 52.31 to $52.61 \mathrm{~kg} / \mathrm{km}^{2}$, which is close to that of nutrient retention in summer $(52.07$ $\left.52.33 \mathrm{~kg} / \mathrm{km}^{2}\right)$, but lower than in spring $\left(53.08-54.38 \mathrm{~kg} / \mathrm{km}^{2}\right)$ and autumn $(52.77$ $\left.53.57 \mathrm{~kg} / \mathrm{km}^{2}\right)$. Compared with other seasons, the level of nutrient retention in winter for six decades $\left(42.83-45.85 \mathrm{~kg} / \mathrm{km}^{2}\right.$ ) was the lowest (Fig. 11).

Except for the southeastern and northeastern parts of Guizhou, the annual nutrient retention increased in most areas during 1960-2017 (Fig. 12e). An increasing trend in the spring nutrient retention was observed in most areas of Guizhou (Fig. 12a). The summer nutrient retention declined in most areas and only small areas in the northwestern, western, and southeastern parts exhibited an increasing trend (Fig. 12b). The autumn nutrient retention decreased in the western and southern parts, whereas it increased in the central, northern and southwestern parts (Fig. 12c). Except for the southwestern, central, and southeastern parts, the winter nutrient retention increased in most parts of Guizhou (Fig. 12d). 


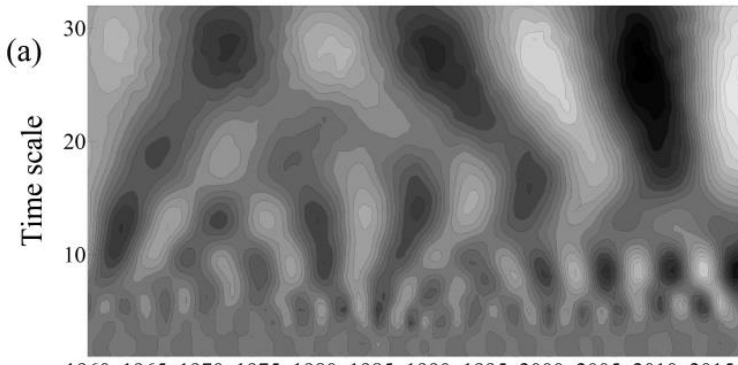
Spring

$1960196519701975 \quad 19801985199019952000200520102015$

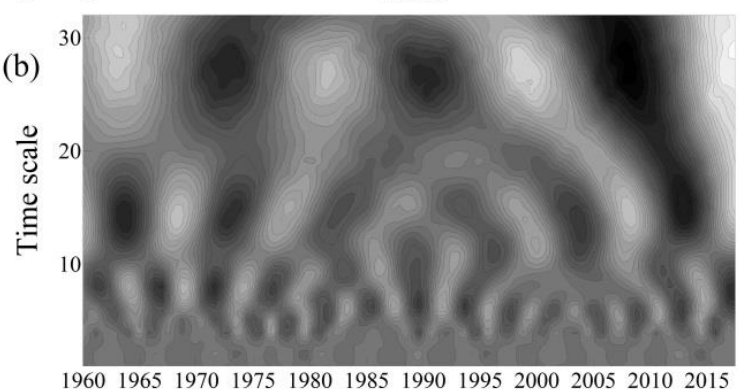

Summer

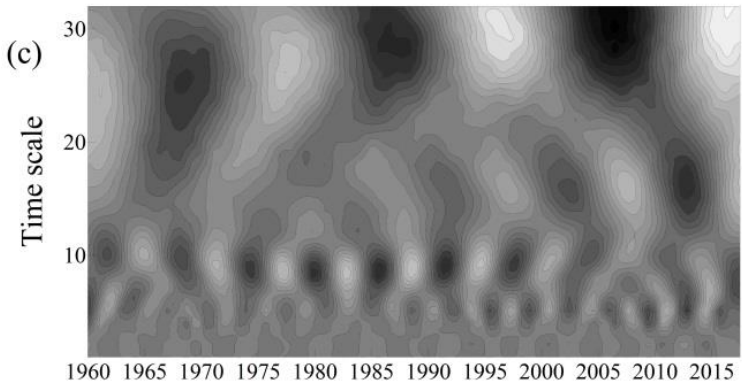

Autumn

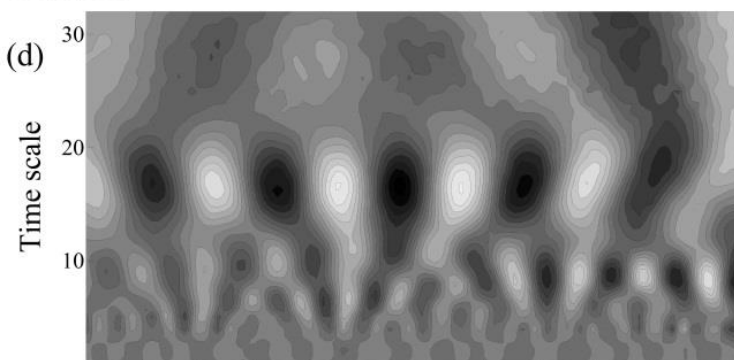

196019651970197519801985199019952000200520102015

$$
\text { Winter }
$$

Years

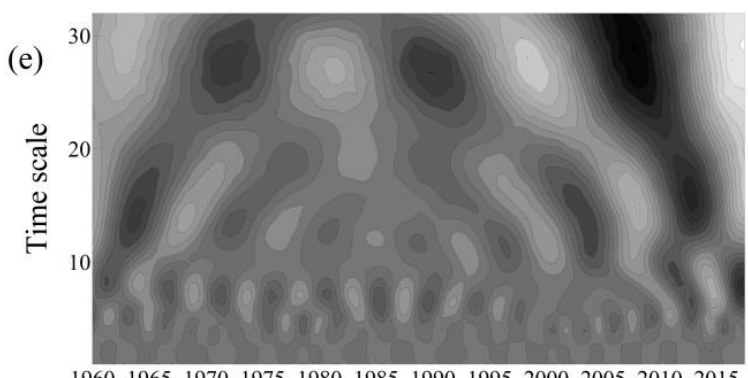

Year
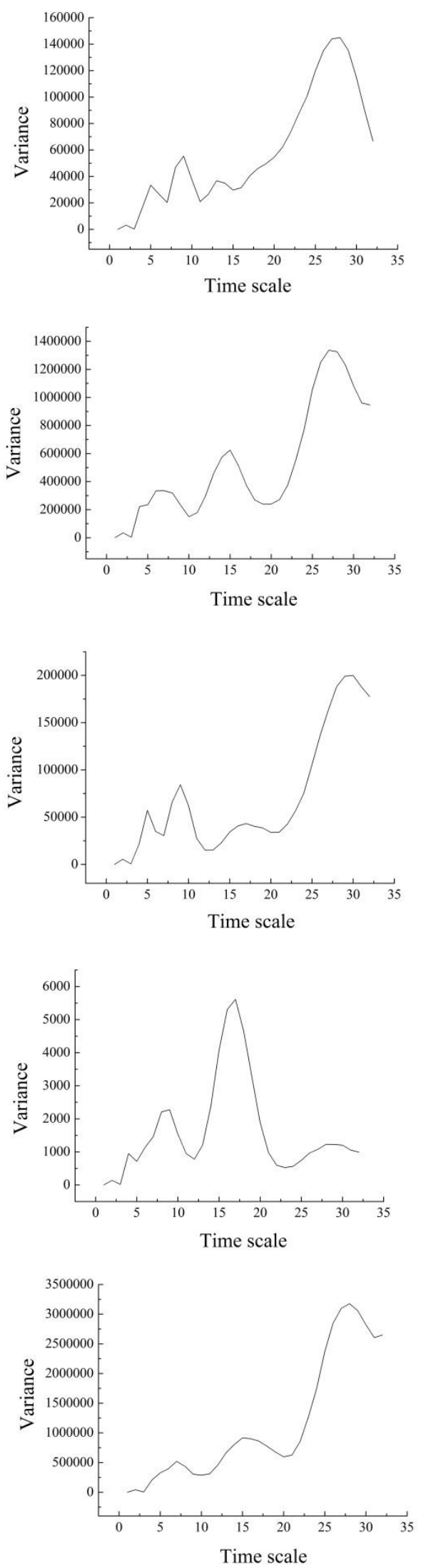

Figure 9. Periodicity of the soil retention change in Guizhou at annual and seasonal scales from 1960 to 2017 
Only one periodic oscillation was observed in the spring, summer, autumn, and annual nutrient retention changes in Guizhou and the highest peak occurred in 28a (Fig. 13a, b, c,e). There were two periodic oscillations in the winter nutrient retention change in 10a and 28a (highest peak) (Fig. 13d).

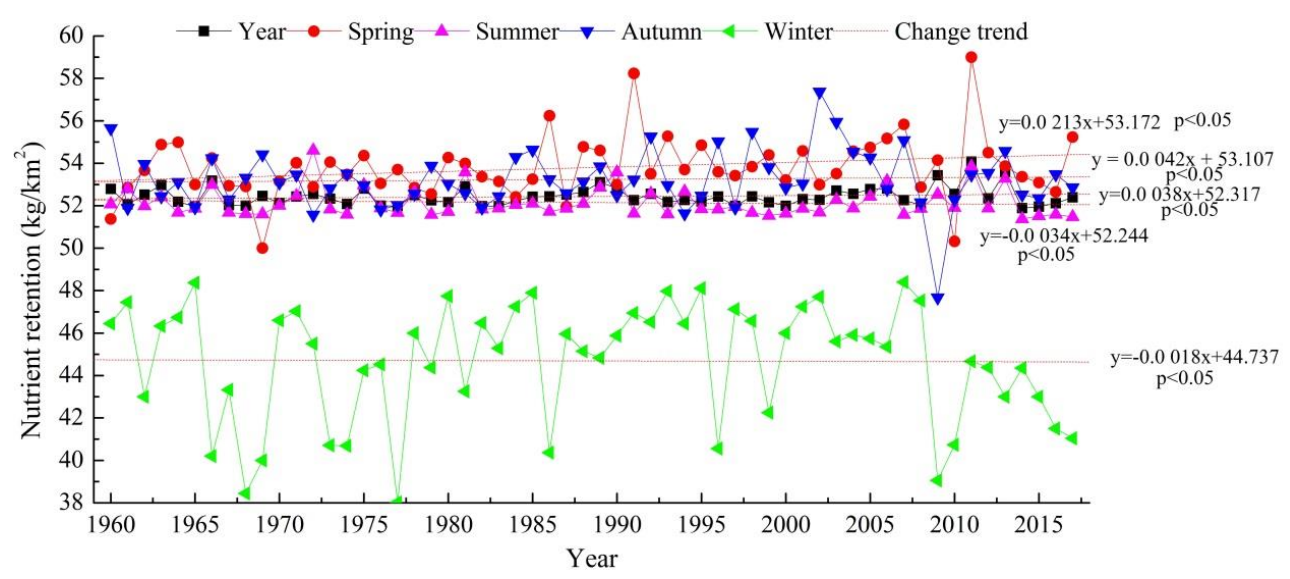

Figure 10. Inter-annual change in the nutrient retention in Guizhou from 1960 to 2017

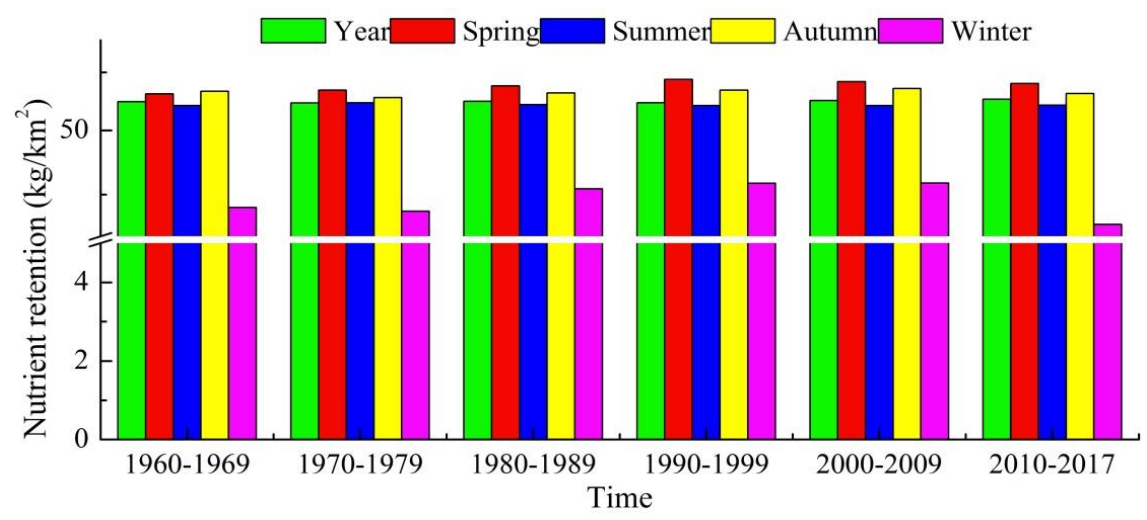

Figure 11. Changes in the nutrient retention in Guizhou for six decades

\section{Discussion}

\section{Impacts of climate change on FES}

The significant impact of climate change on FES in Guizhou is demonstrated in the study, as evidenced by the results of Bai et al. (2019) and Bucak et al. (2018). Nevertheless, there are some clear differences in the impact of climate change on different FES. Those similar results have been obtained in the research of Jorda-Capdevila et al. (2019) and Bai et al. (2019). Precipitation and evaporation are important climatic factors influencing changes in the water yield (Terrado et al., 2014; Fan et al., 2018). The decline in the annual, spring, and autumn precipitation in Guizhou was higher than the evaporation from 1960 to 2017, which led to a downward trend of the annual, spring, and autumn water yield. The increases in the winter and summer water yield were closely related to the increases in the winter and summer precipitation between 1960 and 2017 in this region (Table 1). The rainfall erosivity is an essential climatic factor affecting soil retention (Hoyer and Chang, 2014; SánchezCanales et al., 2015). The increases in the annual, summer, and winter rainfall erosivity 
from 1960 to 2017 in Guizhou resulted in an increasing trend of the soil retention for the same periods. Similarly, the decline in the soil retention in spring and autumn were closely related to the decline in rainfall erosivity in spring and autumn (Table 1). In addition, precipitation and evaporation affected the amount of nutrient retention by influencing the surface runoff (Sharp et al., 2014). The increasing trend in the annual, spring, and autumn nutrient retention in Guizhou was related to the decrease in the water yield caused by the larger decrease in precipitation than evaporation from 1960 to 2017. Similarly, the declining trend in nutrient retention in summer and winter was closely related to the increase in the water yield resulting from an increase in precipitation (Table 1). In addition, the spatial pattern of FES change was closely associated with the distribution of changes in climatic factor. For example, the amount of precipitation showed decrease in the west but increase in the east over the last few decades in Guizhou (Zhao et al., 2018), which led to a declining trend in the west but an increasing trend in the east for the change to annual water yield. Similarly, the annual rainfall erosivity exhibited an upward trend in most parts of Guizhou except for west Guizhou (Liu et al., 2012), which contributed to spatial pattern of annual soil retention in this study.

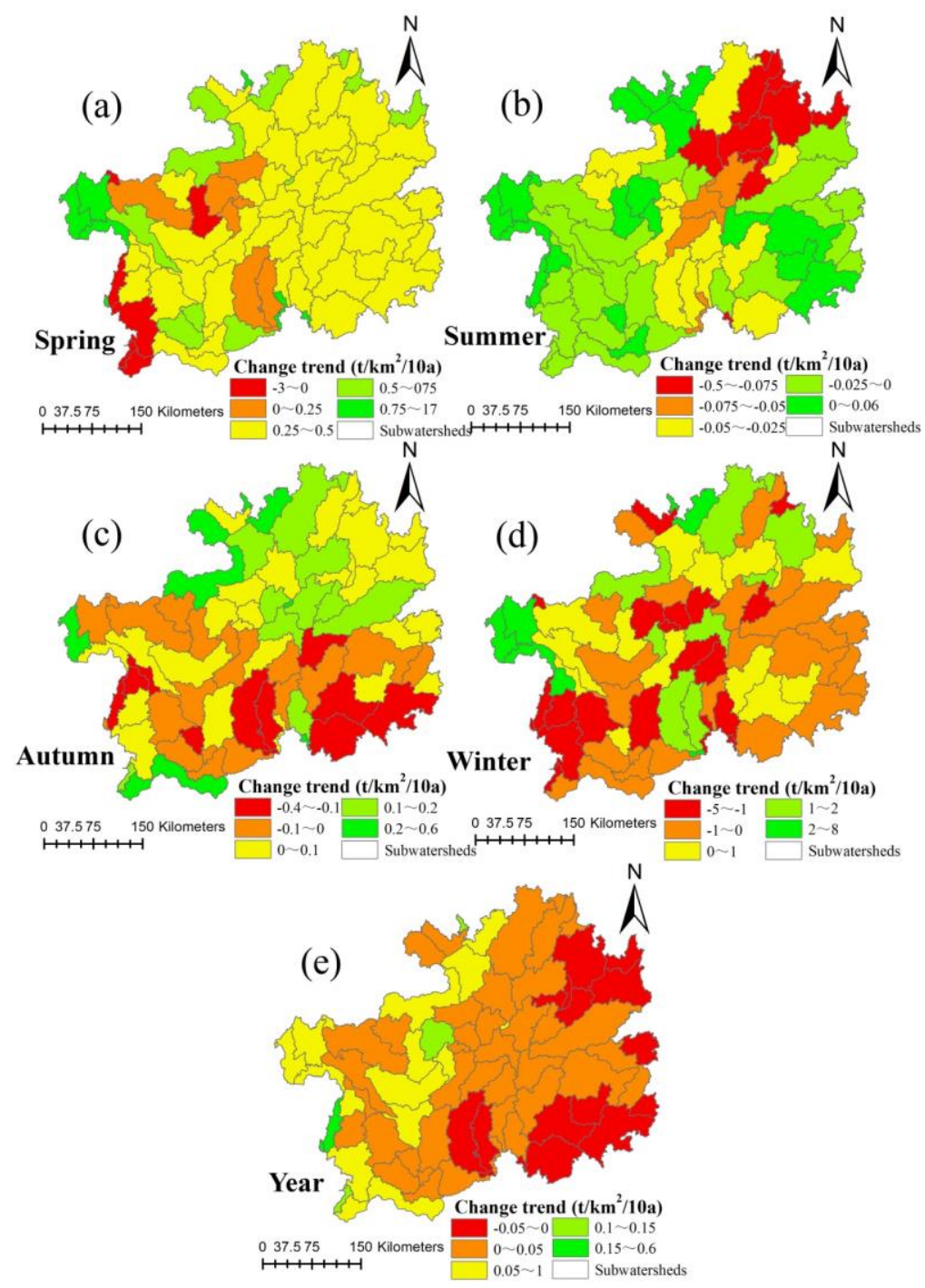

Figure 12. Spatial pattern of the changes in the nutrient retention in Guizhou at annual and seasonal scales from 1960 to 2017 
(a)
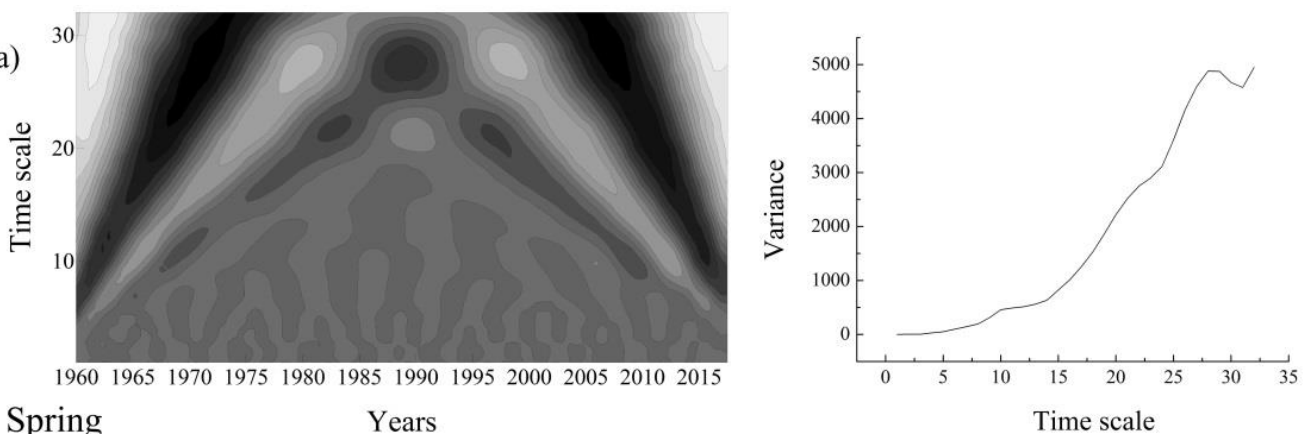

Spring

Years

(b)

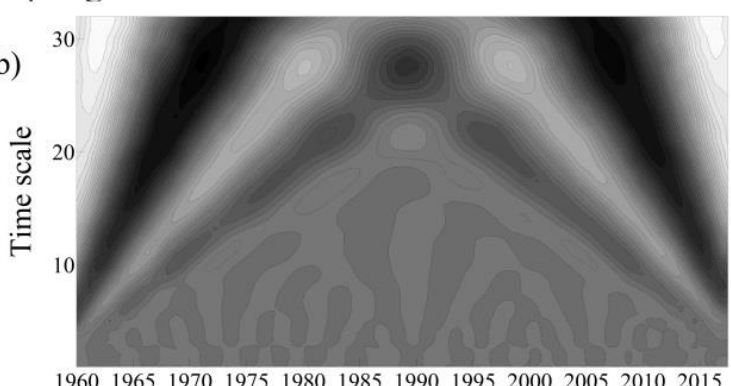

Summer

Years
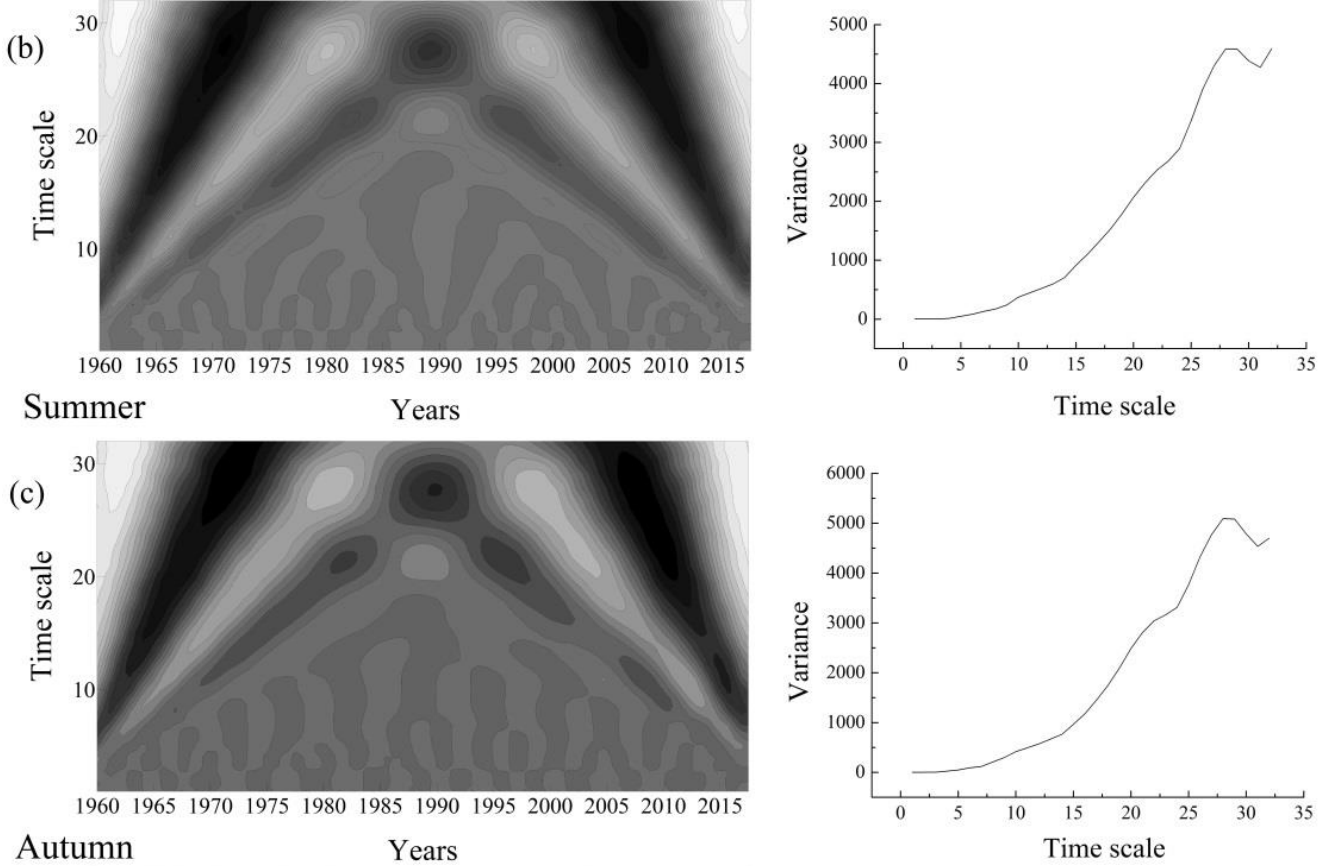

\section{Autumn}

Years

(d)

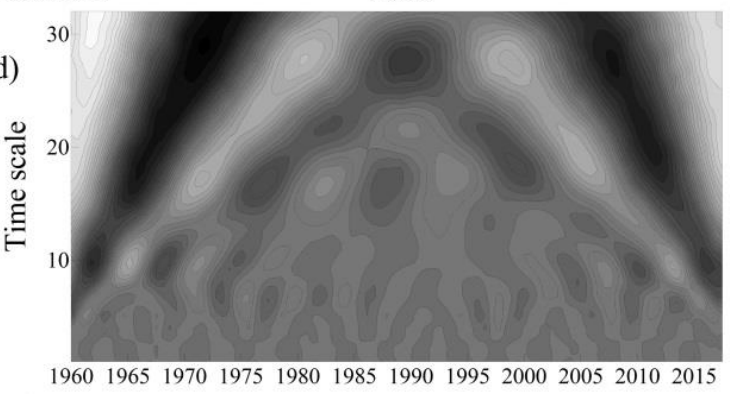

Winter

Years

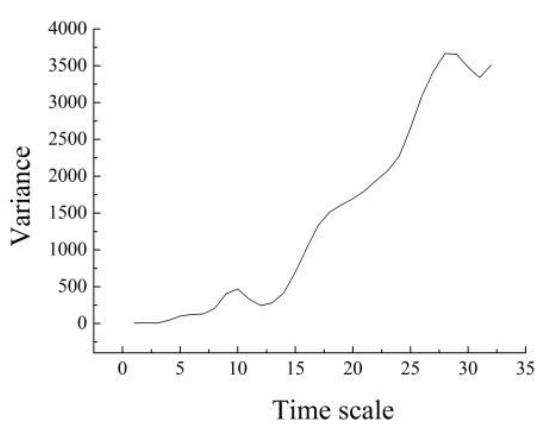

(e)

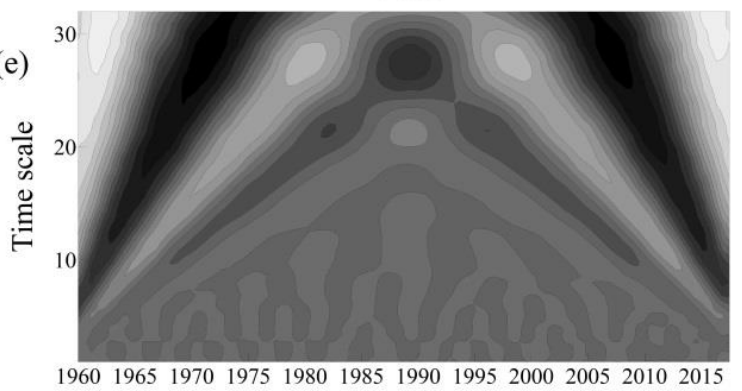

Year

Years

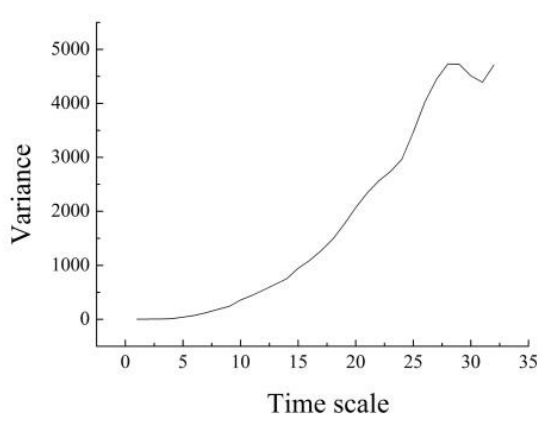

Figure 13. Periodicity of the nutrient retention change in Guizhou at annual and seasonal scales from 1960 to 2017 
Table 1. Changes in climatic factors in Guizhou from 1960 to 2017

\begin{tabular}{c|c|c|c|c|c}
\hline Climatic factors & Annual & Spring & Summer & Autumn & Winter \\
\hline Precipitation (mm/10a) & -7.028 & -4.899 & 2.125 & -8.476 & 4.222 \\
Evaporation (mm/10a) & -1.978 & -0.211 & -4.422 & -0.427 & 3.102 \\
Rainfall erosivity (MJ mm/ha/h/yr/10a) & 61.827 & -28.619 & 85.053 & -5.115 & 11.187 \\
\hline
\end{tabular}

\section{Ecosystem management under the influence of climate change}

The sustainable management of natural and human ecosystems is an important aspect when dealing with the negative impacts of climate change (Gutierrez et al., 2016; Anandhi, 2017). We should reduce the consumption of freshwater and improve the availability of freshwater for agricultural and industrial production, given the decreasing water yield in Guizhou. In addition, different types of water infrastructure should be established to minimize the negative influence of a decline in water yield. Although the annual precipitation in Guizhou exhibited a downward trend from 1960 to 2017, the annual rainfall erosivity exhibited an increasing trend. Thus, the natural vegetation cover (such as forest and grassland) should be improved in the study area to improve the soil retention capacity in the future. Furthermore, terraced fields are recommended for Guizhou because they are suitable for the mountainous area. Moreover, although the nutrient retention caused by the reduction in precipitation exhibited an increasing trend, it will result in decreasing water yield, which requires balancing the relationship between water yield and nutrient retention. The water yield should be increased to avoid a substantial decrease in nutrient retention in the future.

\section{Conclusions}

Decreasing trends in the annual, spring, and autumn water yield and soil retention were observed, whereas increasing trends occurred for the water yield and soil retention in summer and winter from 1960 to 2017 in Guizhou. The nutrient retention increased annually and in the spring and autumn, whereas it decreased in summer and winter. The peak period in terms of annual changes in the water yield, soil retention, and nutrient retention in Guizhou occurred in 28a. There were apparent differences in the peak periods of the water yield and soil retention change in spring, summer, and autumn. The peak period of the nutrient retention change in the four seasons was 28a. There was significant spatial heterogeneity in terms of the changes in the water yield, soil retention, and nutrient retention at annual and seasonal scales in Guizhou. The changes to FES in different Karst landforms are supposed to be highlighted in the future research. In this sense, it is necessary for scholars to focus attention on the combined effects of land use and climate changes on the temporal FES changes in the future.

\footnotetext{
Acknowledgements. Project supported by the Joint Fund of the National Natural Science Foundation of China and the Karst Science Research Center of Guizhou province (Grant No. U1812401), the Science and Technology Foundation of Guizhou Province ([2020]1Y152), the Academic Cultivation and Exploration Innovation Project of Guizhou Institute of Technology (No. [2017]5789-23), and the Scientific Research Foundation of the Guizhou Institute of Technology (XJGC20190666). We thank Yue Liu and Siying Chen (Guizhou Institute of Technology) for part of the data analyses in the revised manuscript.
}

Conflict of interests. The authors declare no conflict of interests. 


\section{REFERENCES}

[1] Allen, R. G., Pereira, L. S., Raes, D., Smith, M. (1998): Crop evapotranspiration: guidelines for computing crop water requirements. - FAO irrigation and drainage, Paper 56. Food and Agriculture Organization of the United Nations, Rome.

[2] Anandhi, A. (2017): CISTA-A: conceptual model using indicators selected by systems thinking for adaptation strategies in a changing climate: case study in agro-ecosystems. Ecological Modelling 345: 41-55.

[3] Bai, Y., Ochuodho, T. O., Yang, J. (2019): Impact of land use and climate change on water-related ecosystem services in Kentucky, USA. - Ecological Indicators 102: 51-64.

[4] Bangash, R. F., Passuello, A., Sanchez-Canales, M., Terrado, M., López, A., Elorza, F. J., Ziv, G., Acuña, V., Schuhmacher, M. (2013): Ecosystem services in Mediterranean river basin: climate change impact on water provisioning and erosion control. - Science of the Total Environment 458: 246-255.

[5] Bartomeus, I., Ascher, J. S., Wagner, D., Danforth, B. N., Colla, S., Kornbluth, S., Winfree, R. (2011): Climate-associated phenological advances in bee pollinators and bee pollinated plants. - Proceedings of the National Academy of Sciences of the United States of America 108: 20645-20649.

[6] Bucak, T., Trolle, D., Tavşanoğlu, Ü. N., Çakıroğlu, A. İ., Özen, A., Jeppesen, E., Beklioğlu, M. (2018): Modeling the effects of climatic and land use changes on phytoplankton and water quality of the largest Turkish freshwater lake: Lake Beyşehir. Science of the Total Environment 621: 802-816.

[7] Budyko, M. I., Miller, D. H. (1974): Climate and life. - Academic Press, New York.

[8] Cerretelli, S., Poggio, L., Gimona, A., Takob, G., Boke, S., Habte, M., Coull, M., Peressotti, A., Black, H. (2018): Spatial assessment of land degradation through key ecosystem services: the role of globally available data. - Science of the Total Environment 628: 539-555.

[9] Charlier, J. B., Ladouche, B., Maréchal, J. C. (2015): Identifying the impact of climate and anthropic pressures on karst aquifers using wavelet analysis. - Journal of Hydrology 523: 610-623.

[10] Costanza, R., Bohensky, E., Butler, J. R. A., Bohnet, I., Delisle, A., Fabricius, K., Gooch, M., Kubiszewski, I., Lukacs, G., Pert, P., Wolanski, E. (2011): A scenario analysis of climate change and ecosystem services for the Great Barrier Reef. - Treatise on Estuarine and Coastal Science 12: 305-326.

[11] Costanza, R., de Groot, R., Sutton, P., van der Ploeg, S., Anderson, S. J., Kubiszewski, I., Faeber, S., Turner, R. K. (2014): Changes in the global value of ecosystem services. Global Environmental Change 26: 152-158.

[12] Dittrich, A., von Wehrden, H., Abson, D. J., Bartkowski, B., Cord, A. F., Fust, P., Hoyer, C., Kambach, S., Meyer, M. A., Radzevičiūtègh, R., Nieto-Romero, M., Seppelt, R., Beckmann, M. (2017): Mapping and analysing historical indicators of ecosystem services in Germany. - Ecological Indicators 75: 101-110.

[13] Dvarskas, A. (2018): Mapping ecosystem services supply chains for coastal Long Island communities: implications for resilience planning. - Ecosystem Services 30: 14-26.

[14] Fan, M., Shibata, H., Chen, L. (2018): Spatial conservation of water yield and sediment retention hydrological ecosystem services across Teshio watershed, northernmost of Japan. - Ecological Complexity 33: 1-10.

[15] Fu, Q., Li, B., Hou, Y., Bi, X., Zhang, X. (2017): Effects of land use and climate change on ecosystem services in Central Asia's arid regions: a case study in Altay Prefecture, China. - Science of the Total Environment 607: 633-646.

[16] Gosling, S. N. (2013): The likelihood and potential impact of future change in the largescale climate-earth system on ecosystem services. - Environmental Science \& Policy 27: S15-S31. 
[17] Grimm, N. B., Groffman, P., Staudinger, M., Tallis, H. (2016): Climate change impacts on ecosystems and ecosystem services in the United States: process and prospects for sustained assessment. - Climatic Change 135: 97-109.

[18] Gutierrez, D., Akester, M., Naranjo, L. (2016): Productivity and sustainable management of the humboldt current large marine ecosystem under climate change. - Environmental Development 17: 126-144.

[19] Han, H., Luo, X., You, R., Luo, X., Chen, Y. (2016): Analysis of water purification function in the Pearl river basin in Guizhou province using InVEST model. - Journal of Nanjing Forestry University (Natural Sciences Edition) 40: 87-92 (in Chinese).

[20] Han, H., Dong, Y. (2017a): Assessing and mapping of multiple ecosystem services in Guizhou Province, China. - Tropical Ecology 58: 331-346.

[21] Han, H., Dong, Y. (2017b): Spatio-temporal variation of water supply in Guizhou Province, China. - Water Policy 19: 181-195.

[22] Han, H., Gao, H., Huang, Y., Chen, X., Chen, M., Li, J. (2019): Effects of drought on freshwater ecosystem services in poverty-stricken mountain areas. - Global Ecology and Conservation 17: e00537.

[23] Han, H., Liu, Y., Gao, H., Zhang, Y., Wang, Z., Chen, X. (2020): Tradeoffs and synergies between ecosystem services: a comparison of the karst and non-karst area. - Journal of Mountain Science 17: 1221-1234.

[24] Hoyer, R., Chang, H. (2014): Assessment of freshwater ecosystem services in the Tualatin and Yamhill basins under climate change and urbanization. - Applied Geography 53: 402-416.

[25] Huang, L., Liao, F., Lohse, K., Larson, D. M., Fragkias, M., Lybecker, D., Baxter, C. V. (2019): Land conservation can mitigate freshwater ecosystem services degradation due to climate change in a semi-arid catchment: the case of the Portneuf River catchment, Idaho, USA. - Science of the Total Environment 651: 1796-1809.

[26] Jorda-Capdevila, D., Gampe, D., García, V. H., Ludwig, R., Sabater, S., Vergoñós, L., Acuña, V. (2019): Impact and mitigation of global change on freshwater-related ecosystem services in Southern Europe. - Science of the Total Environment 651: 895908.

[27] Karp, D. S., Tallis, H., Sachse, R., Halpern, B., Thonicke, K., Cramer, W., Mooney, H., Polasky, S., Tietjen, B., Waha, K., Walz, A., Wolny, S. (2015): National indicators for observing ecosystem service change. - Global Environmental Change 35: 12-21.

[28] Lam, V. W. Y., Cheung, W. W. L., Reygondeau, G., Sumaila, R. (2016): Projected change in global fisheries revenues under climate change. - Scientific Reports 6: 32607.

[29] Lee, H., Lautenbach, S. (2016): A quantitative review of relationships between ecosystem services. - Ecological Indicators 66: 340-351.

[30] Liu, B., Tao, H., Song, C., Guo, B., Shi, Z. (2012): Temporal and spatial variations of rainfall erosivity in southwest China from 1960 to 2009. - Advances in Earth Science 27: 499-509 (in Chinese).

[31] Lobell, D. B., Schlenker, W., Costa-Roberts, J. (2011): Climate trends and global crop production since 1980. - Science 333: 616-620.

[32] Lorencová, E., Frélichová, J., Nelson, E., Vačkářd, D. (2013): Past and future impacts of land use and climate change on agricultural ecosystem services in the Czech Republic. Land Use Policy 33: 183-194.

[33] Ma, Z., Liu, J., Zhang, S., Chen, W., Yang, S. (2013): Observed climate changes in southwest China during 1961-2010. - Advances in Climate Change Research 4: 30-40.

[34] Mahmoud, S. H., Gan, T. Y. (2018): Impact of anthropogenic climate change and human activities on environment and ecosystem services in arid regions. - Science of the Total Environment 633: 1329-1344.

[35] Maia, A. G., Miyamoto, B. C. B., Garcia, J. R. (2018): Climate change and agriculture: do environmental preservation and ecosystem services matter? - Ecological Economics 152: $27-39$. 
[36] Millennium Ecosystem Assessment (MA) (2005): Ecosystems and human well-being: the assessment series (four volumes and summary). - Island Press, Washington, DC.

[37] Mooney, H., Larigauderie, A., Cesario, M., Elmquist, T., Hoegh-Guldberg, O., Lavorel, S., Mace, G. M., Palmer, M., Scholes, R., Yahara, T. (2009): Biodiversity, climate change, and ecosystem services. - Current Opinion in Environmental Sustainability 1: 46-54.

[38] Qiao, X., Gu, Y., Zou, C., Xu, D., Wang, L., Ye, X., Yang, Y., Huang, X. (2019): Temporal variation and spatial scale dependency of the trade-offs and synergies among multiple ecosystem services in the Taihu Lake Basin of China. - Science of the Total Environment 651: 218-229.

[39] Rau, A. L., von Wehrden, H., Abson, D. J. (2018): Temporal dynamics of ecosystem services. - Ecological Economics 151: 122-130.

[40] Redhead, J. W., May, L., Oliver, T. H., Hamel, P., Sharp, R., Bullock, J. M. (2018): National scale evaluation of the InVEST nutrient retention model in the United Kingdom. - Science of the Total Environment 610: 666-677.

[41] Rocca, M. E., Brown, P. M., MacDonald, L. H., Carrico, C. M. (2014): Climate change impacts on fire regimes and key ecosystem services in Rocky Mountain forests. - Forest Ecology and Management 327: 290-305.

[42] Sánchez-Canales, M., López-Benito, A., Acuña, V., Ziv, G., Hamel, P., Chaplin-Kramer, R., Elorza, F. J. (2015): Sensitivity analysis of a sediment dynamics model applied in a Mediterranean river basin: global change and management implications. - Science of the Total Environment 502: 602-610.

[43] Sharp, R., Tallis, H. T., Ricketts, T., Guerry, A. D., Wood, S. A., Chaplin-Kramer, R., Nelson, E., Ennaanay, D., Wolny, S., Olwero, N., Vigerstol, K., Pennington, D., Mendoza, G., Aukema, J., Foster, J., Forrest, J., Cameron, D., Arkema, K., Lonsdorf, E., Kennedy, C., Verutes, G., Kim, C. K., Guannel, G., Papenfus, M., Toft, J., Marsik, M., Bernhardt, J., Griffin, R., Glowinski, K., Chaumont, N., Perelman, A., Lacayo, M., Mandle, L., Hamel, P., Vogl, A. L., Rogers, L., Bierbower, W., Denu, D., Douglass, J. (2014): InVEST User's Guide. - The Natural Capital Project, Stanford University, University of Minnesota, the Nature Conservancy, and World Wildlife Fund.

[44] Su, C., Fu, B. (2013): Evolution of ecosystem services in the Chinese Loess Plateau under climatic and land use changes. - Global and Planetary Change 101: 119-128.

[45] Terrado, M., Acuña, V., Ennaanay, D., Tallis, H., Sabater, S. (2014): Impact of climate extremes on hydrological ecosystem services in a heavily humanized Mediterranean basin. - Ecological Indicators 37: 199-209.

[46] Torrence, C., Compo, G. P. (1998): A practical guide to wavelet analysis. - Bulletin of the American Meteorological Society 79: 61-78.

[47] Trumbore, S., Brando, P., Hartmann, H. (2015): Forest health and global change. Science 349: 814-818.

[48] Wang, H., Zhou, S., Li, X., Liu, H., Chi, D., Xu, K. (2016): The influence of climate change and human activities on ecosystem service value. - Ecological Engineering 87: 224-239.

[49] Wei, F. (2007): Modern climate statistics diagnosis and prediction. - China Meteorological Press, Beijing (in Chinese).

[50] Yi, H., Shu, H. (2012): The improvement of the Morlet wavelet for multi-period analysis of climate data. - Comptes Rendus Geoscience 344: 483-497.

[51] Zhang, W. B., Fu, J. S. (2003): Rain erositivity estimation under different rainfall amount. - Recourses Science 25: 35-41 (in Chinese).

[52] Zhang, Y., Zhou, Z., Yan, L. (2015): On climate change characteristics of the typical ecologically vulnerable Karst area in the recent 25 years: a case study area of the central Guizhou Province. - Journal of Anhui Normal University (Natural Science) 38: 474-478 (in Chinese). 
[53] Zhao, Z., Luo, Y., Yu, J., Luo, X., Yang, Y. (2018): Analysis of precipitation variation characteristics and barycenter shift in Guizhou Plateau during 1960-2016. - Journal of Geo-information Science 20: 1432-1442 (in Chinese).

[54] Zhou, W. Z., Liu, G. H., Pan, J. J., Feng, X. F. (2005): Distribution of available soil water capacity in China. - Journal of Geographical Sciences 15: 3-12.

\section{APPENDIX}

Meteorological stations in Guizhou

\begin{tabular}{c|c|c|c|c|c}
\hline $\begin{array}{c}\text { Meteorological } \\
\text { stations }\end{array}$ & $\begin{array}{c}\text { Meteorological } \\
\text { stations }\end{array}$ & $\begin{array}{c}\text { Meteorological } \\
\text { stations }\end{array}$ & $\begin{array}{c}\text { Meteorological } \\
\text { stations }\end{array}$ & $\begin{array}{c}\text { Meteorological } \\
\text { stations }\end{array}$ & $\begin{array}{c}\text { Meteorological } \\
\text { stations }\end{array}$ \\
\hline Hezhang & Yinjiang & Sansui & Tongzi & Zhenyuan & Tianzhu \\
Weining & Shiqian & Taijiang & Chishui & Yuping & Jinping \\
Shuicheng & Cenggong & Jianhe & Xishui & Tongren & Qinglong \\
Puan & Jiangkou & Leishan & Daozhen & Wanshan & Xingren \\
Panxian & Shibing & Liping & Zhengan & Nayong & Guanling \\
Wuchuan & Qianxi & Zhenfeng & Dafang & Zhenning & Ziyun \\
Yanhe & Zhijin & Wangmo & Renhuai & Xiuwen & Baiyun \\
Dejiang & Anshun & Xingyi & Zunyi & Qingzhen & Huishui \\
Songtao & Liuzhi & Anlong & Jinsha & Pingba & Longli \\
Bijie & Puding & Ceheng & Zunyixian & Guiyang & Huaxi \\
Xifeng & Changshun & Wudang & Meitan & Guiding & Dushan \\
Kaiyang & Fuquan & Luodian & Fenggang & Kaili & Sandu \\
Suiyang & Huangping & Pingtang & Wengan & Duyun & Libo \\
Yuqing & Majiang & Rongjiang & Sinan & Danzhai & Congjiang \\
\hline
\end{tabular}

